Federal Reserve Bank of Minneapolis

Quarterly Review

Spring 1980

The Future of Monetary Policy:

The Rational Expectations Perspective (p.l)

A Case for Branch Banking in Montana (p.8)

District Conditions (p. 18)

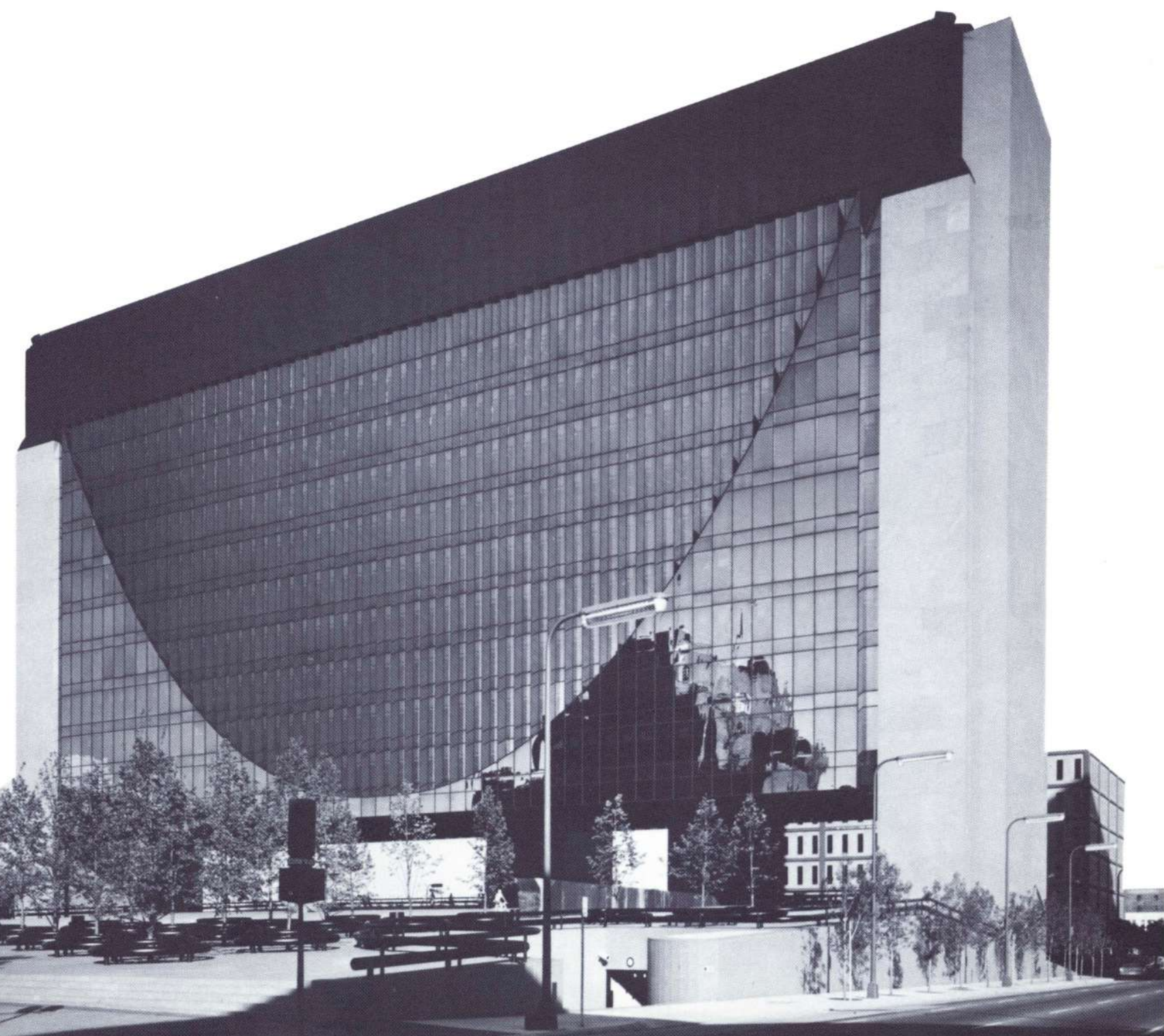


Federal Reserve Bank of Minneapolis Quarterly Review vol. 4, No. 2

This publication primarily presents economic research aimed at improving policymaking by the Federal Reserve System and other governmental authorities.

Produced in the Research Department. Edited by Arthur J. Rolnick, Kathleen S. Rolfe, and Alan Struthers, Jr. Graphic design by Phil Swenson and charts drawn by Mary K. Steffenhagen, Graphic Services Department.

Address requests for additional copies to the Research Department, Federal Reserve Bank, Minneapolis, Minnesota 55480.

Articles may be reprinted if the source is credited and the Research Department is provided with copies of reprints.

The views expressed herein are those of the authors and not necessarily those of the Federal Reserve Bank of Minneapolis or the Federal Reserve System. 


\title{
The Future of Monetary Policy: The Rational Expectations Perspective ${ }^{*}$
}

\author{
Mark H. Willes, President \\ Federal Reserve Bank of Minneapolis
}

Nobody is very happy with the conduct of monetary policy. The economy has performed badly, particularly in terms of inflation and the large costs that go with it. And the near-term outlook for the performance of the economy is grim. Many critics accuse the monetary authorities of failing to deal effectively with the problems we have faced, and virtually every policymaker admits that, in hindsight, we have made some mistakes that have added to our economic woes.

The critical questions now are, Can and will the Federal Reserve do better in the future? My own assessment is that we clearly can do better than we have, but it is too soon to tell whether we really will. Not that we don't all want to do better. I am absolutely convinced that all of my colleagues strive diligently to recommend and pursue those policies that are best designed to improve economic conditions. But we don't all agree on what best policies are. It is these intellectual and analytical differences that raise questions about the future directions of monetary policy.

\section{Two Basic Questions}

Recent experience has raised two fundamental questions about the ability of the monetary authorities to manage the economy. One is how the Federal Reserve can best control the monetary aggregates. The other, more important question is whether policymakers can trade off lower rates of real growth and employment

\footnotetext{
*A paper presented at the Allied Social Science Association Annual Meeting in Atlanta, Georgia, December 29, 1979, and previously published by the Center for Research in Government Policy and Business (Reprint CS-7). I gratefully acknowledge the assistance of my staff, and Arthur Rolnick in particular, in preparing these remarks.
}

(or higher rates of unemployment) for lower rates of inflation.

The question of how to control the monetary aggregates has created considerable controversy. Recognizing the need to improve its operating procedures, the Fed recently announced a new procedure that is designed to control the aggregates by manipulating bank reserves. Many people have doubts, however, about the effectiveness of this new procedure, for in some ways it appears to be just the old one in disguise. It may take a while before this controversy is resolved. Within a year or so, we will have enough experience with the new procedure to decide whether the Fed has controlled the aggregates better than it did under the old procedure and whether the new approach has made the difference. I have some serious misgivings about how we are conducting this new experiment, but I am willing to wait and hope we refine the process so that it becomes a real success.

The question of the existence of a trade-off between inflation and unemployment (the Phillips curve relationship) has also stirred a major controversy, and this is the most basic disagreement facing economic policymakers, since it goes to the heart of what we can and cannot do. The controversy actually started several years ago, sparked by a new theory of expectations that has radical implications for policy analysis. Advocates of this theory, rational expectations, contend that there is no simple trade-off between inflation and unemployment and that analyzing economic policy is much more subtle and complex than standard macroeconometric models lead us to believe. If the rational 
expectations theory is correct, some of the main problems of the last several years are really only outgrowths of the problems of the last ten years, problems caused in part by inadequate theory which led to counterproductive policy. The implication is that we could have done more good by doing less - that is, by making fewer attempts to offset economic fluctuations. The corollary implication is that future monetary policy will be more effective if it is less active. In my judgement, it is the resolution, or lack thereof, of the controversy surrounding this point that will determine both the direction and the success of monetary policy. Consequently, what I would like to do is discuss why I think rational expectations should be taken seriously and why it has such fundamental implications for the conduct of monetary policy.

\section{Economic analysis needs \\ a theory of expectations}

In the last few years, policymakers as well as academicians have been recognizing the importance of expectations in economic decision making. They have found that expectations can be a key factor in a wide range of consumption, investment, and policymaking problems. In fact, it is hard to imagine an economic problem which does not include expectations. Most economic problems are inherently dynamic; in some way, time is involved. Time can be a cost of production, an element in the planning horizon, or an influence on preferences. Whatever the problem, though, once time becomes a factor, expectations must also, for what we think is going to happen tomorrow will affect the choices we make today.

The consumption-saving problem faced by economic agents illustrates the key role of expectations in the decision process. One of the most successful theories for explaining consumption and saving has been the permanent-income hypothesis. Roughly speaking, it says that today's consumption and saving depend not only on today's spendable income, but on expected future income as well. Expected life-span, expected future tax liability, and expected earning potential can all affect economic agents' decisions on how much income to consume now and how much to save for the next period. People who expected a shorter life-span, a new tax on consumption, or a higher salary might greatly increase their current consumption or saving.

Investment decisions are another kind of problem in which expectations play an obviously important role. What individuals invest today clearly depends on what returns and what risks they expect over the life of the investment. One major influence on their expected returns and risks is their expected future tax liabilities. For example, congressional consideration of a windfall profits tax has undoubtedly increased the risks and reduced the investment individuals are willing to make in the oil industry.

It would be easy to enumerate many other economic problems that are inherently dynamic and require a theory of expectations, but perhaps it is unnecessary. At least to some extent, economists have always agreed that expectations are critical at this level of analysis. Only recently, though, have they become aware that expectations are also important for analyzing economic stabilization policies.

Like most other economic problems, stabilization policies must be analyzed in a dynamic framework. What government does today-how it raises taxes, spends its revenues, and finances its deficits - affects the economic environment of the future. (And the government presumably cares about the future economy as well as the present.) Once again, where time is a factor, expectations are critical. People's decisions today depend on expectations of the future. Because government policies affect future outcomes, they affect people's expectations and thus affect people's current decisions. If today's policy actions do not take expectations into account, they may not have their intended effects.

A theory of expectations, therefore, is a major ingredient for almost any analysis of economic behavior. In particular, it's a prerequisite for any model that is going to explain how economic decisions are made and how optimal government policies are formulated.

\section{The Adaptive Expectations Theory}

Recognizing the importance of developing a theory of expectations has proved much less controversial than agreeing on the best theory. Many have believed that the adaptive expectations theory, which assumes that expectations are simply an extrapolation of past trends, is the best we could do. But recent theoretical challenges, as well as recent experience, have raised serious doubts about the validity of modeling expectations this way.

Model builders' initial attempts at constructing a theory of expectations were based on relatively simplistic assumptions. These attempts assumed either that agents expected no change or that they expected 
the change tomorrow to be the same as it was today. After some experimenting, econometricians found that they could get better fitting equations if they assumed that expected changes would be equal to a weighted average of past changes. This adaptive expectations model went virtually unchallenged until the 1970s.

The substantive issues economists first discussed about this theory were not those dealing with the validity of adaptive expectations but rather those questioning the size of the weights and the length of the lag distribution. If the weights were small and the lags were long, models that used the adaptive expectations scheme predicted that the trade-off between inflation and unemployment was quite favorable. Stimulative policy only had to increase inflation a little in order to lower real wages and boost employment and production for a relatively long time. If the weights were large and the lags were short, however, the inflationunemployment trade-off was much less favorable. Then reducing real wages required significantly more inflation, and the employment and production benefits didn't last nearly as long.

The discussion of weights and lags was not trivial as long as the adaptive expectations scheme remained unchallenged. The debate about the characteristics of the lag distribution continues even today as we hear both policymakers and economists argue about the costs and benefits of stimulating a recessionary economy that is suffering from double-digit inflation. Such debates, though, ignore more fundamental issues.

While some economists are still trying to estimate the trade-off between inflation and unemployment, others are questioning the validity of the underlying theory. Models based on adaptive expectations, which worked well in the 1960 s, failed dramatically in the 1970 s. In the early 1970 s such models predicted, with a high degree of confidence, that the United States could drive its unemployment rate down to 4 percent if it were only willing to live with a 4 to 5 percent rate of inflation; with a 5 to 6 percent rate of inflation, it could virtually eliminate unemployment. There was some debate about whether this trade-off could be repeatedly exploited, but most economists agreed that at least in the short run such a trade-off existed. The actual 1970s inflation and unemployment statistics were a serious rejection of these models. Whether by design or not, we got much more inflation than most expected, yet unemployment climbed above 9 percent instead of falling to zero as predicted.
Inflation and Unemployment

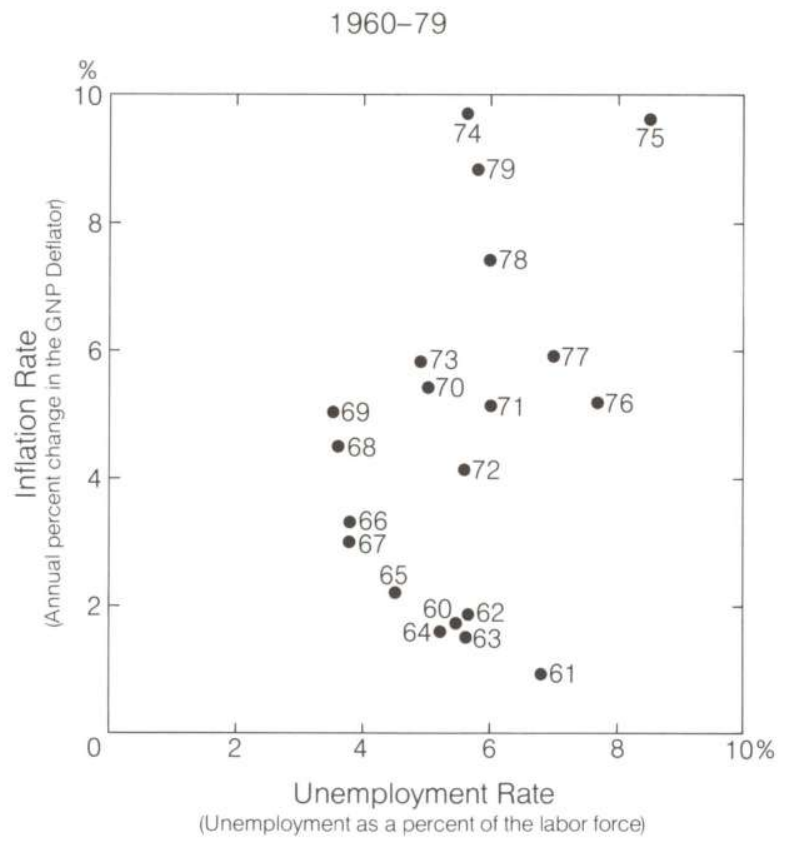

Sources: U.S. Departments of Commerce and Labor

To some, this empirical rejection of standard macroeconometric models came as no surprise because the theory of adaptive expectations is inconsistent with the rest of economic theory. The fundamental principle underlying virtually all economic theory has been that agents always do the best they can for themselves, given their income, wealth and technological constraints. With the resources and tools available, firms produce until any extra output brings less revenue than the extra cost of production - that is, until maximum profits are collected. Likewise, individuals consume until any extra current consumption is worth less than tomorrow's consumption-that is, until consumption is maximized over time. And likewise, workers continue working until any extra income they earn is worth less to them than the leisure they forego. The theory of adaptive expectations is not consistent with this principle of optimization. The adaptive expectations equations used for forecasting generally imply, that agents don't optimize. They imply, instead, that agents can be systematically fooled so that obvious profits can go uncollected. 


\section{Adaptive expectations are irrational}

A few examples will illustrate how agents fail to optimize when they base their expectations just on historical relationships, as the adaptive expectations scheme assumes.

Suppose the government announced a new higher rate of price supports for wheat. And suppose this policy change was advertised well in advance and had complete congressional approval. The wheat farmers who based their production and storage decisions only on past price behavior would make some very big mistakes - just as they would if they ignored the price implications of a new report on the Russian wheat harvest or a recent change in weather. The wheat farmers who based their decisions on such readily available information, as well as on the historical behavior of past prices, would obviously do much better.

In adaptive forecasting schemes, agents also fail to optimize in the wage bargaining process. If workers or their unions use only historical data to forecast future inflation, they can easily be misled into working for wages with lower purchasing power than desired. Suppose the government announced that the accumulated federal deficit in the 1980s was going to grow twice as fast as it did in the 1970s and that the Federal Reserve was going to buy most of this new debt. Those unions that assumed prices were going to behave just as they did in the 1970s would agree to contracts that allowed their members' real wages to decline. Those unions that paid attention to the correlation between government financing and inflation would make much better deals for their members.

Under adaptive expectations, agents also fail to optimize when OPEC announces a change in its pricing policy. Suppose OPEC planned to double its price tomorrow. Firms that used a lot of energy would seriously understate their expenses if they only looked at the historical prices of oil-not at probable future prices. The efficient firm would take this new information into account and make a much better decision.

By not using available information about current and future events, agents who form expectations adaptively can make some very obvious mistakes, leaving very obvious profits uncollected. The criticism of the adaptive expectations theory, though, goes much deeper. It is not only that mistakes are obvious, but also that they persist. Thomas Sargent (1976a, pp. 316-18) has shown that when agents form expectations adaptively, one can easily devise a future path for any policy variable that can systematically and forever fool them. Adaptive expectations, therefore, are generally irrational expectations.

\section{The Rational Expectations Theory}

Recognizing the nonoptimality of the adaptive expectations approach, several researchers began to take a new theory pioneered by John Muth (1961) more seriously. Muth's idea was to model expectations the same way economists model other economic behavior: by assuming agents maximize their objective functions subject to the constraints they face. With this in mind, Muth assumed that agents' subjective probability distributions are equal to the objective or actual probability distributions plus a random term, the variance of which depends on the information available to agents. He defined such expectations as rational. Rationality, therefore, is not perfect foresight; people can make mistakes. In fact, people can make lots of mistakes, but they will not be systematically wrong.

By assuming that agents use information efficiently, Muth was able to construct a theory of expectations that was consistent with the rest of economic theory. Like other economic theories, Muth's implies that obvious uncollected profits do not persist. Constructing such a theory, however, was not the breakthrough that led a significant number of economists to abandon standard models.

The major breakthrough came when Robert Lucas showed that rational expectations models can explain a correlation between inflation and unemployment, a correlation similar to that represented by the Phillips curve. Standard macroeconomics began with the notion that we could not explain unemployment with classical equilibrium models. In a nonstochastic, frictionless classical model, in which agents optimize and markets clear, monetary policy is neutral. There is no correlation between inflation and unemployment, for there is no unemployment; in equilibrium, all who want to work can work. As the money supply increases and prices rise, real wages remain unchanged. Workers concerned about the purchasing power of wages raise their money wage demands, but firms are willing to pay the higher wages because their prices have increased. In the new equilibrium, nominal wages rise by the same amount as prices, leaving employment and production unchanged.

To explain the inflation-unemployment correlation represented by the Phillips curve, macroeconomists 
have argued that we had to abandon the assumptions of clearing markets and optimizing agents. James Tobin (1947), for example, assumed that agents were "irrational" in the labor markets. He recognized that such agents were incompatible with optimizing agents, but he contended that the only way to construct a model consistent with the correlation between inflation and unemployment was to drop the optimizing assumption. The nonoptimality assumption also implied that the correlation represented a trade-off that could be exploited by expansionary fiscal and monetary policies. We could reduce unemployment if we were willing to pay the price of a higher inflation rate.

Lucas' contribution was to show that the classical model was abandoned prematurely (Lucas 1972, 1975). He proved that an essentially classical model one based on the classical principle of optimizing agents and clearing markets - could generate a correlation between inflation and unemployment. $\mathrm{He}$ did this by extending classical theory to include uncertainty and information costs. In Lucas' new classical approach, agents face an information problem. In general, they do not know whether a change in the price of their labor is a real change (due, say, to an increase in demand for their services) or simply a reflection of a general rise in all prices. If an increase in the price of their labor occurred because of a real change in supply or demand, then agents would want to respond somehow. For instance, they might adjust the number of hours they were willing to work. If the increase in the price of their labor was merely the result of inflation, however, then they wouldn't want to respond. The problem they face is that they don't know whether any specific change in their own price is real or not, so they don't know how to respond. When agents face this kind of uncertainty, some of them respond as if the price changes were real and not just the result of a general change in the price level. Under these conditions, unexpected movements in prices can generate real effects, such as the correlation between inflation and unemployment.

\section{Challenges to Macro Models and Policies}

The policy implications of this new micro theory are obviously much different from those of standard macroeconomics. The theory suggests that there is no simple way to stimulate demand and move the economy along the Phillips curve toward higher output. In fact, Sargent and Neil Wallace (1975) have shown that even within a standard macro framework, the inflation-unemployment trade-off doesn't exist when rational expectations are imposed. While policies can have real effects, the effects are much more subtle and complex than standard models have led us to believe.

Sargent and Wallace first showed that in ad hoc macroeconomic models, under certain conditions, rational expectations imply that policy is neutral. [They define an ad hoc model as one that is not derived from a consistent set of assumptions about individuals' and firms' objective functions and available information (Sargent and Wallace 1975, p. 241).] If the public and monetary authority have access to the same information and if agents have identical preferences, then "the probability distribution of output is independent of the deterministic money supply rule in effect" (p. 242). In an ad hoc model, one nonrandom money supply rule is as good as another.

They went on to show that, when these assumptions are relaxed, monetary policy can affect the distribution of output, but constructing the right policy nevertheless becomes very hard. When the monetary authority has more information than the public, for example, policy can affect the variance of output (though not the mean). To choose the right policy, however, the monetary authority must know precisely how the public's information differs from its own. When the public is slow to learn about a policy change, for another example, the monetary authority can affect real output. But here again, the monetary authority must know precisely what the public knows, plus how it learns, before it can devise the right policy. Policy analysis no longer rests on estimating a simple relationship between inflation and unemployment. It now requires the policymaker to know precisely how information sets differ and how people learn. As Sargent and Wallace point out, this is such a subtle task it is likely to be an intractable econometric problem.

These results of the rational expectations research are often misinterpreted. Many think the theory of rational expectations says that monetary policy does not matter, that whatever the monetary authority tries to do, rational agents will undo. This, however, is the wrong implication. More accurately, the SargentWallace results are a strong indictment of ad hoc macro models because they point out how little these models tell us about the impact of inflation. We know that inflationary policies matter. We know, for example, that inflation makes the real return on money 
negative; therefore, inflation must generally cause a decline in all other real rates. We also know that inflation affects the value of agents' endowments and that not all agents are identical; therefore, inflation must affect real consumption and saving decisions. Further, we know that agents' information sets differ among themselves and differ from the information sets of the monetary authorities; therefore, inflation must have an effect on the distribution of output. Yet, ad hoc macro models tell us nothing about these effects; they are not explicit enough to capture the impact of monetary policy. Without more explicit theories, we cannot even begin to understand how inflation affects the economy and how to construct appropriate policies.

\section{The Dominating Theory}

Some have alleged that the assumptions behind rational expectations are too unrealistic, that people just are not smart enough to be rational. They argue that people don't have enough information to make rational forecasts or that they don't know how to use the information efficiently. Both allegations are misleading. Most useful theories, after all, make some superficially unrealistic assumptions. Furthermore, rationality does not depend on how much information agents have, but only on how they use their information. No matter how little information they have, therefore, agents have enough to satisfy the premises of rational expectations. The substantive issue is thus whether they use their information efficiently. Using information efficiently means only that agents cannot be systematically wrong forever. This is a realistic enough assumption. Although absolutely efficient use of information may not be descriptively realistic, would it be more realistic to assume people use information inefficiently? That is, would it be more realistic to assume people are 95 percent, 50 percent, or 25 percent efficient? I doubt it. Any number would be difficult to defend strictly on realistic grounds. Furthermore, anything less than 100 percent efficiency implies obvious uncollected profits, since people can be consistently fooled. Surely this implication cannot be justified on grounds of realism.

Most economists would agree that only empirical results can provide tests for choosing among competing theories. In economics, however, testing alternative theories is usually not very easy. Choosing between rational and adaptive expectations is a classic example. On the one hand, advocates of rationality contend that their theory can explain the shifting Phillips curve observed in the 1970s. The curve shifted, they believe, because inflation did not continue to surprise people. On the other hand, proponents of adaptive expectations claim that the Phillips curve shifted for reasons that had little to do with inflationary expectations. They argue that changes in the composition of the work force and the pricing policies of OPEC were the major causes of the instability in the Phillips curve. Once these extraneous factors are taken into account, their autoregressive equations fit the 1970 s very well.

Based on goodness of fit, then, neither theory of expectations is clearly superior. But Sargent (1976b) has shown that in a period when only one policy rule is in effect, this criterion can never be used to determine which theory is better. An adaptive expectations model can be constructed to fit the data just as well as a rational expectations model when there has not been a change in the policy rule.

Sargent's findings, however, do not rule out all tests; they only make the task more difficult. A way to test the validity of these theories is to test their stability under alternative policy rules. The only study I know of that has performed such a test found the rational expectations model superior. Salih Neftci and Sargent (1978) identified a break in monetary policy rule in 1968. After estimating a standard version of a macroeconometric model for the years before 1968, they applied the model to the years after 1968 and found that it failed dramatically. It was not stable. The rational expectations results, while not spectacular, were considerably better. The model marginally passed a test of stability. This is an important test because an economic model must remain invariant when policy changes if it is to be useful for evaluating policies. With the empirical evidence available, then, the rational expectations theory cannot be dismissed, nor should its policy implications be ignored.

\section{Conclusion}

The rational expectations theory gives us a new perspective on policy analysis. For the first time, it gives us a coherent approach to modeling expectations that may be applied to many aspects of economic analysis. Equally important, the rational expectations theory has some very negative implications. It says that we currently know very little about the appropriate use of economic policies. It says that macroeconomists have to develop more explicit models of economic behavior. 
It says that the answers we seek are much more subtle and complex than we once believed.

Because we know so little, economists and policymakers should be considerably humbler in their policy prescriptions. Simple correlations between inflation and unemployment, for instance, cannot be reliable guides to policy. At most, we can say that since policy actions can easily add to the economic uncertainty, whatever rules we happen to choose should be well defined and well understood. For policymakers to advocate much more than this will require significant theoretical and empirical breakthroughs in research. In the meantime, it seems to me the best we can do is to follow policy rules which are stable and long-run. Who knows; we might even like the results we get.

\section{References}

Lucas, Robert E., Jr. 1972. Expectations and the neutrality of money. Journal of Economic Theory 4 (April): 103-24.

1975. An equilibrium model of the business cycle. Journal of Political Economy 83 (December): 1113-44.

Muth, John F. 1961. Rational expectations and the theory of price movements. Econometrica 29 (July): 315-35.

Neftci, Salih, and Sargent, Thomas J. 1978. A little bit of evidence on the natural rate hypothesis from the U.S. Journal of Monetary Economics 4 (April): 315-19.

Sargent, Thomas J. 1976a. Interest rates and expected inflation: a selective summary of recent research. Explorations in Economic Research: Occasional Papers of the National Bureau of Economic Research 3 (Summer): 303-25.

1976b. The observational equivalence of natural and unnatural rate theories of macroeconomics. Journal of Political Economy 84 (June): 631-40.

Sargent, Thomas J., and Wallace, Neil. 1975. "Rational" expectations, the optimal monetary instrument, and the optimal money supply rule. Journal of Political Economy 83 (April): 241-54.

Tobin, James. 1947. Money wage rates and employment. In The new economics: Keynes' influence on theory and public policy, ed. Seymour Harris, pp. 572-87. New York: Knopf. 